\title{
3D Analysis of Facial Morphology of a Colombian Population Compared to Adult Caucasians
}

\author{
Sonia Bravo-Hammett ${ }^{1} \quad$ Ludovica Nucci $^{3} \quad$ Teti Christou $^{1} \quad$ Juan Fernando Aristizabal ${ }^{2}$ Chung How Kau ${ }^{1, \odot}$ \\ ${ }^{1}$ Department of Orthodontics, University of Alabama Birmingham, \\ United States \\ 2Universidad Del Valle, San Dernando, Cali, Colombia \\ ${ }^{3}$ Multidisciplinary Department of Medical-Surgical and Dental \\ Specialties, University of Campania “Luigi Vanvitelli,” Naples, Italy

\begin{abstract}
Address for correspondence Chung $\mathrm{H}$. Kau, BDS, MScD, MBA, PhD, MOrthEdin, FDSGlas, FAMS(Ortho), FFDIre, FDSEdin, FACD, FICD, ABO, Cert (Ortho) Department of Orthodontics, University of Alabama Birmingham, Suite 305, 1919 7th Avenue,
\end{abstract} \\ South Birmingham AL35294, United States (e-mail: ckau@uab.edu).
}

Eur J Dent:2020;14:342-351

\begin{abstract}
Keywords

$-3 \mathrm{D}$

- facial morphology

$-3 d M D$

- Colombian face

- Hispanic soft tissue

Objective The purpose of this study involves describing the facial morphology of a Colombian population with three-dimensional (3D) imaging, and comparing their facial morphology with the Caucasian to create a database for this ethnicity.

Materials and Methods The study, which included 135 subjects selected from the Valle University in Cali, Colombia, and 535 Caucasian subjects selected from the FaceBase-Data (1U01DE024449-01), was funded by the National Institute of Dental and Craniofacial Research. All images were taken in the natural head position (NHP) and captured using a stereo-photogrammetric camera system (3dMDface) to obtain a 3D image of each patient. The subjects were between 19 to 31 years of age, with a normal body mass index (BMI), and no craniofacial deformities. All images were plotted and analyzed using the $3 \mathrm{dMDVultus}$ software to calculate linear and angular measurements. Standard deviation (SD) and means were calculated for each measurement and analyzed using $t$-test for different samples.

Results The Hispanic population had wider eyes, more protruded upper and lower lips, wider face, and greater mandibular width. Caucasian females had a more acute full profile, larger middle third, and less protrusive lips. Understanding the facial morphology of different populations would help to establish a better diagnosis and treatment planning for each ethnicity.

Conclusions From this study, the following conclusions may be drawn:

1. The mean values of Colombian males showed greater measurements than females in the majority of measurements.

2. Caucasian females had a more acute full profile, larger middle and lower third, and less protrusive lips.

3. This study showed significant ethnic differences in the linear and angular measurements, showing us the importance of considering these findings in the diagnosis and treatment planning when a Hispanic population is involved. Soft tissue values should reflect the norms according to each ethnic population in order to achieve treatment goals.
\end{abstract}

License terms

(ㅇ) (1) $\ominus \circledast$ 


\section{Introduction}

Enhancement of the facial appearance is one of the most important factors for patient seeking orthodontic treatment. Three-dimensional (3D) imaging in orthodontics has been developing at a fast pace over the past three decades. ${ }^{1-4}$ Traditionally, study models have been used by orthodontists, allowing them to examine malocclusions from many 3D viewpoints. ${ }^{5,6}$ Currently, digitization of 3D models by virtual technologies have been preferred by many clinicians., $, 7,8$ Two-dimensional diagnostic methods, such as lateral cephalometric radiographs and profile photographs, have slowly been replaced by 3D images used to diagnose malocclusions. Facial soft tissues obtained from 3D technology have the advantage of being able to provide orthodontist with a more accurate representation of facial morphologies $4,9,10$ and can be beneficial to better understand, compare, ${ }^{9,11,12}$ and predict outcomes before and after treatment. ${ }^{13-15}$

The paradigm shift in treatment philosophies has existed for nearly three decades. This current shift means that many orthodontists have started to plan from the soft tissues of the face and evaluate the limitations of orthodontic treatment. The key determinant in orthodontic diagnosis and treatment success now lies behind the patient's limits of soft tissue adaptation and contours. ${ }^{16}$ Orthodontists as well as maxillofacial and plastic surgeons may not be able to make decisions for the treatment of racially diverse individuals on the same basis of facial morphologic standards. As a result, knowledge of the facial features and distinctive properties of populations with various racial and ethnic backgrounds is essential information for a clinician. 3D imaging has certainly helped to improve understanding these outcomes. ${ }^{17,18}$

At present, there is little research done in the areas of facial morphology for the Colombian population. However, much research has been done previously in other population types which include Koreans, ${ }^{19}$ Zimbabweans, African Americans, ${ }^{20,21}$ Chinese, ${ }^{15}$ Hungarian, ${ }^{12}$ Egyptian, ${ }^{22}$ Greeks, ${ }^{23}$ Slovenians ${ }^{10}$ to name a few. The results show distinct and important variations for treatment consideration., ${ }^{2,2425}$ While many different groups have been studied using 3D imaging, the Hispanic population has few studies done in facial analysis of soft tissues. Many of the described 3D studies mentioned above have described the facial morphology and carried out comparisons with Caucasian races but have not considered the Hispanic face features.

Some of the pioneers in facial Hispanic research include Canavati ${ }^{26}$ and Kennedy. ${ }^{27}$ They found a higher incidence of dental protrusion in Latin-American children when compared with Caucasian children of 4 to 7 years of age, using cephalometric measurements. Another study by Garcia used cephalometric measurements, ${ }^{28}$ in Mexican-American children using the Downs, Steiner, and Alabama analyses. He concluded that the Mexican-American children had more bimaxillary prognathism than Caucasians as well as a more protrusive dental relationship. Swlerenga et al ${ }^{29}$ analyzed a group of 48 adult Mexican-American patients with parents or grandparents born in Mexico. They concluded from cephalograms that Mexican-American males had longer maxillary and mandibular lengths with a flatter mandibular plane than the Caucasian males. Dentally, both Mexican-American men and women exhibited more protrusive lower incisors than Caucasians. The combination of thicker soft tissues, maxillary skeletal prognathism and dento-alveolar protrusion explain the protrusive lips of Mexican-Americans. ${ }^{30}$

The purpose of this study was to compare the facial morphologies of an adult Caucasian population with the facial morphologies of an adult Colombian population using a 3D surface imaging device.

\section{Materials and Methods}

This was a cross-sectional study. The total population was 135 subjects selected from the Valle University, Cali, Colombia, who voluntarily decided to participate, and 535 Caucasian subjects selected from the Face Database (1U01DE024449-01), which is financed by the National Institute of Dental and Craniofacial Research. The current research was approved by the ethical institutional review board from both universities: Valle and UAB (IRB approval $\mathrm{X} 130701004)$. The subjects were recruited from two sources: (1) patients present for dental treatment in the school of dentistry; (2) students who volunteer to participate.

The final selection of participants was based on selection criteria. A written informed consent was obtained from each individual before the study was completed.

\section{Inclusion Criteria}

The following subjects were included:

1. Participants with Colombian citizenship.

2. Males and females between 19 to 32 years of age.

3. Normal body mass index (BMI) (18.5-24.9).

4. No facial anomalies or syndromes.

5. No gross facial asymmetries at clinical examination.

Subjects with the following were excluded from the study:

1. Subjects with orthodontic treatment.

2. Acquired or inherited dentofacial deformities.

3. Subjects who received orthognathic or plastic surgery.

4. Participants with mental disability and unable to follow instructions.

\section{Sample Size}

The city where the study was performed (Cali, Colombia) has a population over $2,530,756$ inhabitants, which is in accordance with the last census published in 2010. The sample size was calculated using the data and was based on the difference of soft tissue changes expected between Caucasian and the Hispanic population. Taking into account the above information, the sample size needed for this study was 133 individuals.

\section{D Imaging Acquisition}

All images were taken in with patients in natural head posture and the technique has been previously described. ${ }^{31}$ The imaging device used was the 3dMDface system, and the accuracy of the system was between 0.1 to $0.5 \mathrm{~mm} .{ }^{32}$ 


\section{Processing of Data}

All the images were transferred into the 3dMD Vultus software for analysis. ${ }^{33}$ Images with distortion or missing data were excluded. Within the software, each image was first aligned to natural head position (NHP) and locked in this

Table 1 Soft tissue landmarks

\begin{tabular}{|l|l|}
\hline Midsagittal Landmarks & Bilateral Landmarks \\
\hline 1. Trichion & 1. Inner Canthus \\
\hline 2. Glabella & 2. Outer Canthus \\
\hline 3. Nasion & 3. Orbitale \\
\hline 4. Dorsum & 4. Zygion (zygomatic) \\
\hline 5. Pronasale (nasal tip) & 5. Alar base \\
\hline 6. Subnasale & 6. Commissure \\
\hline 7. Philtrum & 7. Gonion \\
\hline 8. Labiale Superius (Upper lip) & 8. Tragus \\
\hline 9. Stomion (Lip junction) & \\
\hline 10. Labiale Inferius (Lower lip) & \\
\hline 11. Labiomental fold & \\
\hline 12. Pogonion & \\
\hline 13. Gnathion & \\
\hline 14. Menton & \\
\hline 15. Chin-throat & \\
\hline
\end{tabular}

position to plot all the landmarks described below and confirmed them in all planes. The landmarks used in this study are the most common soft tissue landmarks reported in previous studies of 3D face analysis, which are mentioned in the literature review (-Table $\mathbf{1}$ ).

\section{Measurements}

Linear and angular measurements were performed, and these were recorded. The linear measurements were calculated from the distance between nasion, as a reference point, to the rest of the facial landmarks ( $\mathbf{- F i g . ~ 1 ) . ~ T h e s e ~ m e a s u r e - ~}$ ments in millimeters contain the maximum, minimum, average and standard deviation (SD) between all the surfaces compared.

\section{Linear Measurements}

The linear measurements in this study included the following

1. Right inner cantus-outer cantus.

2. Left inner cantus-outer cantus.

3. Inter measurements of the cantus of the eyes.

4. Orbital width.

5. Zygomatic width.

6. Alar width.

7. Commissure width

8. Gonial width.

9. Upper third: trichion to nasion $(\mathrm{Tr}-\mathrm{N})$.

10. Middle third: nasion to subnasale (N-Sn).

11. Lower third: subnasale to gnation (Sn-Gn).

12. Length of upper lip: subnasale to stomion (Sn-Sto).

13. Length of lower lip: stomion to mental fold (Sto-Gn).

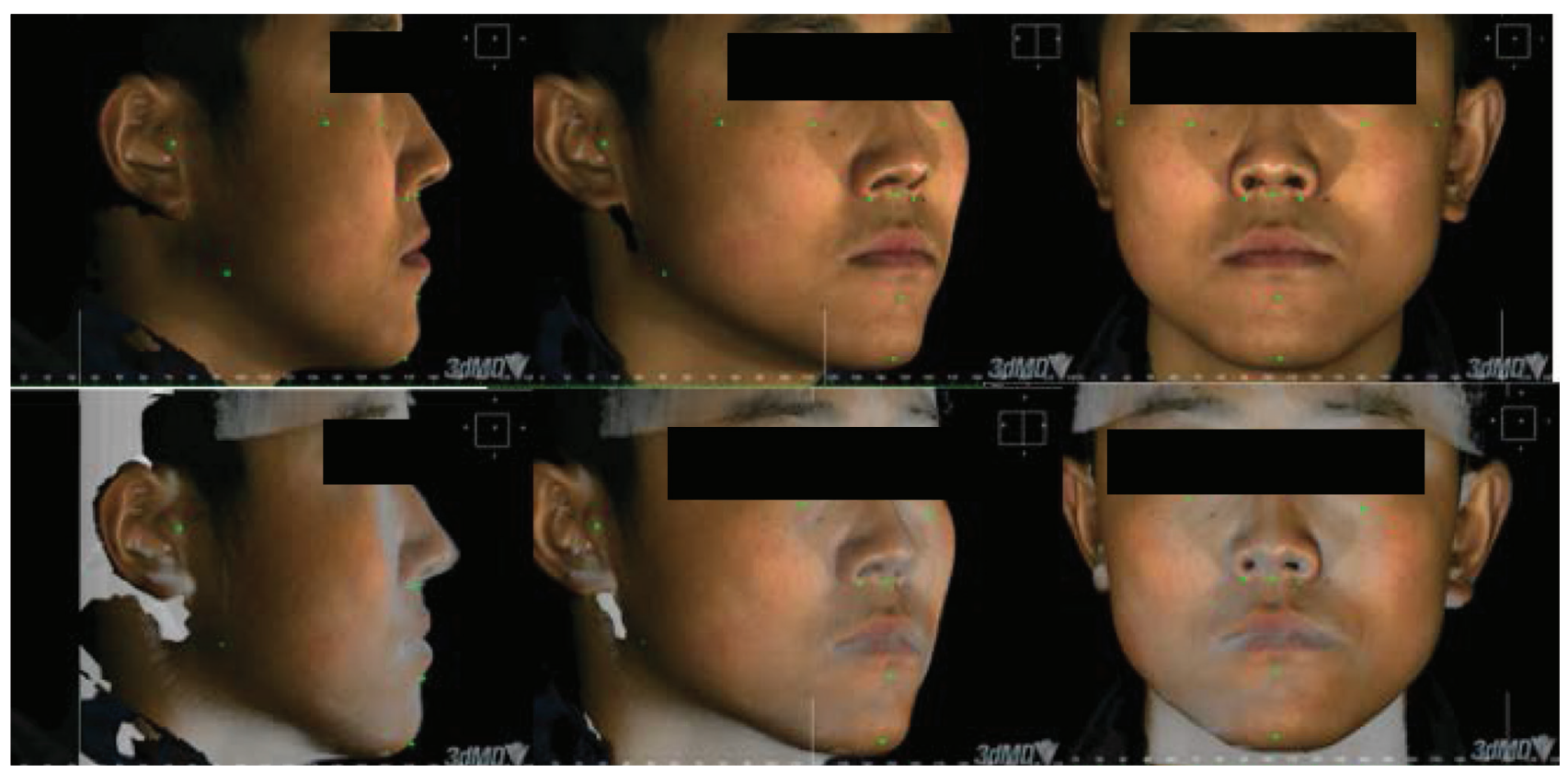

Fig. 1 Figure showing the landmarks on Table 1 to include all points for measurement. 


\section{Angular Measurements}

The angular measurements in the study were as follows:

- Glabela-nasion-dorsum (Gl-Na-Do)

- Pronasale-subnasale-upper lip (Pron-Subn-U-Lip)

- Soft tissue profile: glabela-subnasale-pogonion (G-Sn-Po)

- Full soft tissue: glabela-pronasale-pogonion (G-Pn-Po)

- Mentolabial sulcus angle: lower lip-mentolabial fold to pogonion line (L-lip-Sm-Pg)

\section{Statistical Analysis}

Statistical analysis of the measurements was performed using the statistical package for the social sciences (SPSS $\mathrm{v}$-16). The frequencies, means, and SDs of all the linear and angular measurements were generated. The sample data was analyzed and found to be normally distributed. Independent $t$-test was used to see differences between different groups.

\section{Results}

A total of 170 Colombian adults volunteered to participate in the study and consented to have their 3D images taken; their range of age was from 19 to 31 years. Out of these, 66 were males and 69 females, who filled the selection criteria and had excellent quality in their images.

A total of 31 soft tissue landmarks were used to describe and compare the Colombian population with the norms of the Caucasian parameters. The distance between sets of landmarks were averaged for all patients, and the mean value for each one was used to compare if there were statistically different. To check the operator's reliability and reproducibility,
30 patients were randomly selected and plotted after an interval of 3 days. Statistically, there was no significant difference found in the landmarks used to assess intraexaminer variability $($ Kappa $=0.91)$. The most difficult landmark to reproduce was the gonial point.

\section{Colombian Population Analysis}

The soft tissue analysis of 135 young adult subjects showed a statistically difference between male and females. - Table 1 shows the main differences found between male and female in the Colombian population. The maximum of facial width $(Z y-Z y)$ was wider in males $(143 \mathrm{~mm})( \pm 11.1)$ than in females $(136 \mathrm{~mm})( \pm 5.8)$. Similar findings were found in nose, mouth and mandibular width, where the mean male nose was 4.2 $\mathrm{mm}$ wider than females (males $=35.6 \mathrm{~mm} \pm 2.95$; females $=$ $31.4 \mathrm{~mm} \pm 4.50$ ). The mouth was on average $3.77 \mathrm{~mm}$ smaller in females than males (males $=51.4 \mathrm{~mm} \pm 3.77$; females $=$ $47.6 \mathrm{~mm} \pm 3.33$ ). Additionally, the mandibular width (GoGo) was $12.2 \mathrm{~mm}$ wider in males $(120.6 \mathrm{~mm} \pm 8.27)$ than in females $(108.4 \mathrm{~mm} \pm 7.16)$ ( - Table 2).

With regard to facial proportions, the facial lower horizontal third was larger in males $(71 \mathrm{~mm})$ and females (64.5 mm). Remarkable, the only measurement of females that was larger than males were the upper facial third $(71.09 \mathrm{~mm})(-$ Table 2$)$.

The following table shows the angular measurements in the Colombian population and indicates that the frontonasal angle was 4 degrees bigger in females; the nasolabial and labiomental folds were similar in both genres. Related to profile, the soft tissue profile angle was very similar in both genres when the nose was not included ( - Table 3 ).

Table 2 Soft tissue analysis of a young adult male and female Colombian population

\begin{tabular}{|c|c|c|c|c|c|c|c|c|}
\hline \multirow[t]{2}{*}{ Variable } & \multicolumn{4}{|c|}{ MALES $(n=66)$} & \multicolumn{4}{|c|}{ FEMALES $(n=69)$} \\
\hline & Mean & SD & Min & Max & Mean & SD & Min & Max \\
\hline Right eye & 32.22 & 1.74 & 27.95 & 36.52 & 30.16 & 2.16 & 25.98 & $34.27^{*}$ \\
\hline Left eye & 31.73 & 1.83 & 28.08 & 36.75 & 29.43 & 2.11 & 24.85 & $34.23^{*}$ \\
\hline Intercanthal & 33.69 & 2.82 & 29.17 & 41.60 & 32.98 & 2.70 & 26.48 & 40.24 \\
\hline Orbitale width & 68.86 & 3.34 & 59.53 & 76.26 & 65.56 & 4.58 & 52.60 & $74.71^{* *}$ \\
\hline Zygomatic width & 143.08 & 11.13 & 130.85 & 157.02 & 136.21 & 5.80 & 124.37 & $150.5^{* *}$ \\
\hline Nose width & 35.60 & 2.95 & 29.82 & 42.58 & 31.40 & 4.50 & 19.77 & $38.81^{* *}$ \\
\hline Commissure width & 51.39 & 3.77 & 44.15 & 60.27 & 47.59 & 3.33 & 38.52 & $56.88^{* *}$ \\
\hline Gonial width & 120.58 & 8.27 & 104.93 & 136.97 & 108.42 & 7.16 & 89.58 & $129.2^{* *}$ \\
\hline Upper third & 67.71 & 6.97 & 50.07 & 79.86 & 71.09 & 6.51 & 56.60 & $86.29 * *$ \\
\hline Middle third & 52.64 & 2.69 & 46.77 & 61.50 & 48.50 & 2.86 & 42.01 & $53.85^{* *}$ \\
\hline Lower third & 71.01 & 4.73 & 57.67 & 77.48 & 64.49 & 4.03 & 51.45 & $70.74^{* *}$ \\
\hline
\end{tabular}

Abbreviation: SD, standard deviation.

*statistically significant $0.01 ;{ }^{* *}$ highly significant 0.001 . 
Measurement of the lips and nose in the Colombian sample are found in - Table 3. It indicates that the length of the upper lip was larger in both genres. Males presented bigger lips than females, with a difference of $3.16 \mathrm{~mm}$ on the upper lip and $2.7 \mathrm{~mm}$ on the lower lip.

Relation to E-plane indicates that the upper lip in females was $-2.7 \mathrm{~mm}$ behind the E-line and $-3.7 \mathrm{~mm}$ behind in males; the lower lip was $-0.87 \mathrm{~mm}$ versus $-2 \mathrm{~mm}$ in males, indicating a more protrusive lips in females than males. The following table also shows that males present a more prominent nose, more protrusive maxilla, and more prominent mandible; according to the soft tissue, landmarks compared with measurements calculated to a perpendicular line from nasion as a reference point (See $\boldsymbol{-}$ Table $\mathbf{4}$ and $\boldsymbol{\bullet}$ Fig. $\mathbf{2}$ ).

\section{Comparison of Male Colombians with Caucasian Population}

All 19 measurements analyzed by genre were slightly higher among male Colombians, with the exception of the middle and lower thirds of the face. It is important to notice that the distance of the upper and lower lips related to E-line were more retrusive in the Caucasians $(-6.0 \mathrm{~mm} \pm 1.87 \mathrm{~mm})$ than the Colombian sample $(-3.7 \mathrm{~mm} \pm 2.82 \mathrm{~mm})$.

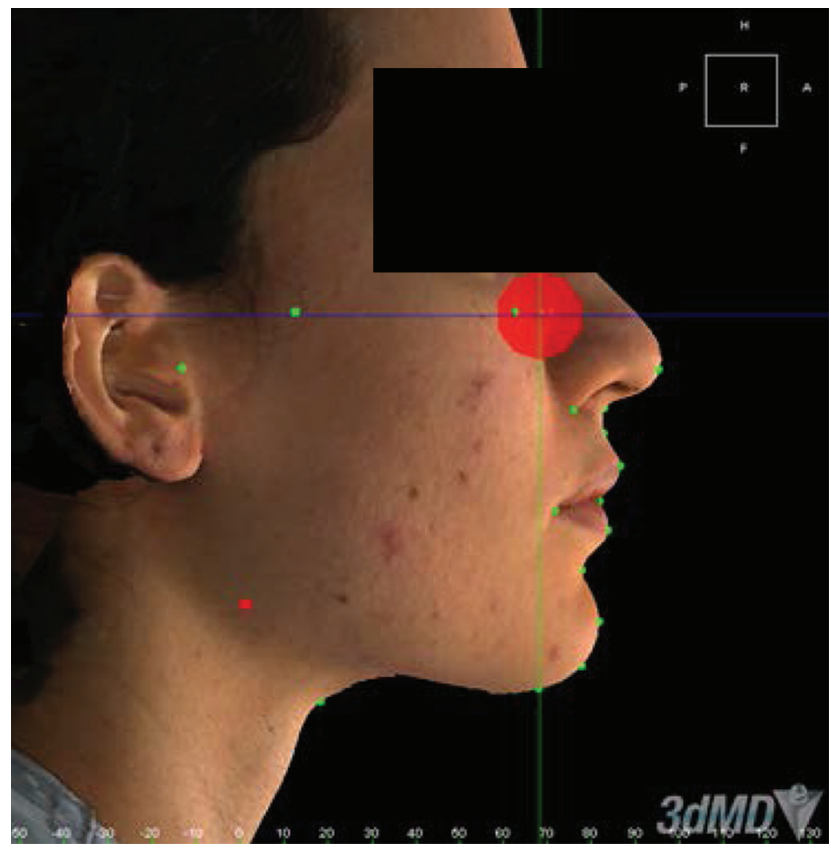

Fig. 2 Example of soft tissue analysis of linear measurements related to nasion point.

Table 3 Soft tissue analysis of angular measurements of young adult Colombian population

\begin{tabular}{|l|l|l|l|l|l|l|l|l|}
\hline \multirow{2}{*}{ Variable } & \multicolumn{4}{|c|}{ Males $(n=66)$} & \multicolumn{3}{c|}{ Females $(n=69)$} \\
\cline { 2 - 10 } & Mean & SD & Min & Max & Mean & SD & Min & Max \\
\hline Nasofrontal angle & 141.92 & 7.18 & 124.18 & 155.78 & 146.43 & 5.76 & 130.01 & $155.64{ }^{*}$ \\
\hline Nasolabial angle & 117.96 & 10.24 & 93.17 & 141.9 & 115.69 & 9.81 & 96.48 & 136.54 \\
\hline Soft tissue profile & 164.85 & 5.49 & 148.92 & 177.59 & 166.28 & 5.7 & 154.47 & 179.61 \\
\hline Full tissue profile & 148.94 & 5.27 & 135.94 & 162.82 & 152.79 & 5.92 & 140.91 & $166.85^{*}$ \\
\hline Labiomental angle & 137.77 & 11.6 & 104.13 & 161.56 & 137.27 & 10.01 & 117.54 & 162.04 \\
\hline
\end{tabular}

Abbreviation: SD, standard deviation.

*statistically significant $0.01 ;{ }^{* *}$ highly significant 0.001 .

Table 4 Soft tissue analysis of linear measurements of young adult Colombian population

\begin{tabular}{|c|c|c|c|c|c|c|c|c|}
\hline & \multicolumn{4}{|c|}{ Males $(n=66)$} & \multicolumn{4}{|c|}{ Females $(n=69)$} \\
\hline Variable & Mean & SD & Min & Max & Mean & SD & Min & Max \\
\hline Length of UL & 24.32 & 2.45 & 18.63 & 29.55 & 21.16 & 2.2 & 15.39 & $25.78 * *$ \\
\hline Length of LL & 19.9 & 2.09 & 15.06 & 26.01 & 17.16 & 1.98 & 12.51 & $21.53^{* *}$ \\
\hline U-lip to E-line & -3.68 & 2.82 & -8.8 & 2.21 & -2.66 & 2.07 & -6.54 & $3.00 *$ \\
\hline L-lip to E-line & -2.05 & 3.19 & -8.3 & 5.36 & -0.83 & 2 & -2.07 & 4.54 \\
\hline Prn to $\mathrm{N}$ & 25.58 & 2.75 & 19.18 & 31.88 & 21.34 & 2.75 & 12.67 & $27.56^{* *}$ \\
\hline $\mathrm{A}^{\prime}$-point* & 10.46 & 3.05 & 3.83 & 17.45 & 8.83 & 3.45 & 0.97 & $18.37^{*}$ \\
\hline B'-point* & 3.77 & 5.21 & -10.2 & 12.85 & 2.66 & 5.1 & -9.28 & 11.57 \\
\hline$P g^{\prime}-N^{*}$ & 5.41 & 6.11 & -11.49 & 18.63 & 3.56 & 6.91 & 16.56 & 14.24 \\
\hline
\end{tabular}

Abbreviation: SD, standard deviation. Measurements related to nasion.

*statistically significant $0.01 ;{ }^{*}$ h hghly significant 0.001 . 
Table 5 Comparison of soft tissue analysis of male adult Colombians compared with a Caucasian population

\begin{tabular}{|c|c|c|c|c|c|c|}
\hline \multirow[t]{2}{*}{ Variable } & \multicolumn{2}{|c|}{ Colombian $(n=66)$} & \multicolumn{2}{|c|}{ Caucasian $(n=535)$} & \multirow[t]{2}{*}{ Dif. } & \multirow[t]{2}{*}{$p$-Value } \\
\hline & Mean & SD & Mean & SD & & \\
\hline R-eye & 32.22 & 1.74 & 29.01 & 1.88 & 3.21 & $<.0001^{* *}$ \\
\hline L-eye & 31.73 & 1.83 & 28.72 & 1.91 & 3.01 & $<.0001^{* *}$ \\
\hline Intercanthal & 33.69 & 2.82 & 32.61 & 2.89 & 1.08 & 0.08 \\
\hline Zygomatic width & 143.08 & 11.13 & 137.32 & 6.2 & 5.76 & $0.001^{*}$ \\
\hline Nose width & 35.6 & 2.95 & 36.08 & 2.45 & -0.48 & 0.39 \\
\hline Commissure width & 51.39 & 3.77 & 50.71 & 3.76 & 0.68 & 0.39 \\
\hline Gonial width & 120.58 & 8.27 & 103.95 & 7.34 & 16.63 & $<.0001^{* *}$ \\
\hline Middle third & 52.64 & 2.69 & 56.56 & 3.9 & -3.92 & $<.0001^{* *}$ \\
\hline Lower third & 71.01 & 4.73 & 72.98 & 5.25 & -1.97 & 0.07 \\
\hline Length of UL & 24.32 & 2.45 & 22.48 & 2.53 & 1.84 & $<.0001^{* *}$ \\
\hline Length of LL & 19.9 & 2.09 & 19.13 & 2.78 & 0.77 & 0.16 \\
\hline Nasofrontal angle & 141.92 & 7.19 & 140.99 & 9.03 & 0.93 & 0.6 \\
\hline Nasolabial angle & 117.96 & 10.24 & 108.15 & 13.18 & 9.81 & $<.0001^{*}$ \\
\hline Soft tissue profile & 164.85 & 5.49 & 165.74 & 4.94 & -0.89 & 0.41 \\
\hline Full tissue profile & 148.94 & 5.27 & 132.81 & 4.73 & 16.13 & $<.0001^{* *}$ \\
\hline Labiomental angle & 137.77 & 11.6 & 129.21 & 11.59 & 8.56 & $<.0001^{* *}$ \\
\hline Nasal prominence & 15.58 & 2.75 & 13.93 & 3.3 & 1.65 & $0.01 *$ \\
\hline U-lip to E-line & -3.68 & 2.82 & -6.03 & 1.87 & 2.35 & $<.0001^{* *}$ \\
\hline L-lip to E-line & -2.05 & 3.19 & -3.95 & 2.01 & 1.90 & $0.0004^{*}$ \\
\hline
\end{tabular}

Abbreviation: SD, standard deviation.

*statistically significant $0.01 ;{ }^{*}$ highly significant 0.001 .

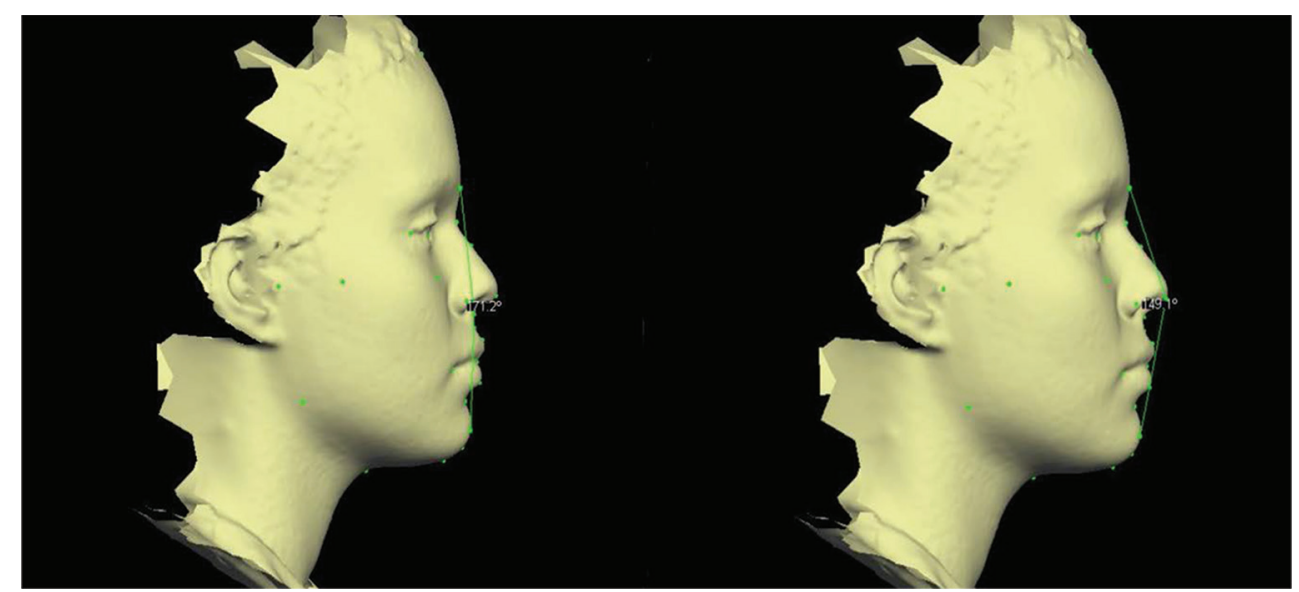

Fig. 3 Soft tissue profile and full tissue profile of a Colombian population.

The zygomatic and gonial width were larger in Hispanics (143 mm and $120.6 \mathrm{~mm}$, respectively). No differences were found on the nose width and soft tissue profile. The profile was almost the same in both populations (Colombian $164.8^{\circ}$ vs. Caucasian $165.7^{\circ}$ ) when the nose was not involved. ( - Fig. 3) It was noticed that the prominence of the nose affected directly the full tissue profile (Colombian $148.9^{\circ}$ vs. Caucasian $132.8^{\circ}$ ) (-Fig. 5).

\section{Comparison of Females Colombians with Caucasian Population}

The Colombian females had a broader face, bigger eyes, wider mandibular width, and more protrusive lips. Caucasian females had a larger middle third of the face $(54.7 \mathrm{~mm}$ vs. $48.5 \mathrm{~mm}$ ). Results showed no significant difference with regard to length of lips, nose, and mouth width (difference: $0.46 \mathrm{~mm},-1.12 \mathrm{~mm}$ and $-0.32 \mathrm{~mm}$, respectively). The distance of the upper and lower lip related to E-line is more retrusive in Caucasians ( $-4.6 \mathrm{~mm}$; SD 1.93); compared with the Colombian females ( $-2.7 \mathrm{~mm}$; SD 2.07), which represents more protrusive lips on the Hispanic sample. It is important to remark that the full soft tissue profile is more obtuse in the Colombian females (Colombian $152.8^{\circ}$ vs. Caucasian $132.1^{\circ}$ ), indicating a less convex profile ( - Table 6 and - Fig. 4 ).

\section{Length of the Lips}

The following graphics represent the main difference in the length of the lips, showing that upper and lower lips are 
Table 6 Comparison of soft tissue analysis of female adult Colombians compared with a Caucasian population

\begin{tabular}{|c|c|c|c|c|c|c|}
\hline \multirow[t]{2}{*}{ Variable } & \multicolumn{2}{|c|}{ Colombian $(n=69)$} & \multicolumn{2}{|c|}{ Caucasian $(n=535)$} & \multirow[t]{2}{*}{ Dif. } & \multirow[t]{2}{*}{$p$-Value } \\
\hline & Mean & SD & Mean & SD & & \\
\hline R-eye & 30.16 & 2.16 & 28.05 & 1.9 & 2.11 & $<.0001^{* *}$ \\
\hline L-eye & 29.43 & 2.11 & 27.77 & 2.01 & 1.66 & $<.0001^{* *}$ \\
\hline Intercanthal & 32.98 & 2.7 & 31.29 & 2.66 & 1.69 & $0.003^{*}$ \\
\hline Zygomatic width & 136.21 & 5.8 & 131 & 5.2 & 5.21 & $<.0001^{* *}$ \\
\hline Nose width & 31.4 & 4.5 & 32.52 & 2.27 & -1.12 & 0.09 \\
\hline Commissure width & 47.59 & 3.33 & 47.91 & 3.37 & -0.32 & 0.65 \\
\hline Gonial width & 108.42 & 7.16 & 96.85 & 6.79 & 11.57 & $<.0001^{* *}$ \\
\hline Middle third & 48.5 & 2.86 & 54.69 & 3.75 & -6.19 & $<.0001^{* *}$ \\
\hline Lower third & 64.49 & 4.03 & 66.43 & 4.85 & -1.94 & 0.05 \\
\hline Length of UL & 21.16 & 2.2 & 20.36 & 2.5 & 0.80 & 0.11 \\
\hline Length of LL & 17.16 & 1.98 & 17.62 & 2.23 & -0.46 & 0.31 \\
\hline Nasofrontal angle & 146.43 & 5.76 & 143.58 & 6.42 & 2.85 & $0.03^{*}$ \\
\hline Nasolabial angle & 115.69 & 9.81 & 102.78 & 14.01 & 12.91 & $<.0001^{* *}$ \\
\hline Soft tissue profile & 166.28 & 5.7 & 164.74 & 4.29 & 1.54 & 0.13 \\
\hline Full tissue profile & 152.79 & 5.92 & 132.12 & 4.14 & 20.67 & $<.0001^{* *}$ \\
\hline Labiomental angle & 137.27 & 10.01 & 128.79 & 13.42 & 8.48 & 0.18 \\
\hline Nasal prominence & 11.34 & 2.75 & 12.3 & 2.78 & -0.96 & 0.1 \\
\hline U-lip to E-line & -2.66 & 2.07 & -4.59 & 2.49 & 1.93 & $0.0002^{*}$ \\
\hline L-lip to E-line & -0.83 & 2 & -2.3 & 2.27 & 1.47 & $0.002^{*}$ \\
\hline
\end{tabular}

Abbreviation: SD, standard deviation.

*statistically significant $0.01 ;{ }^{* *}$ highly significant 0.00 .

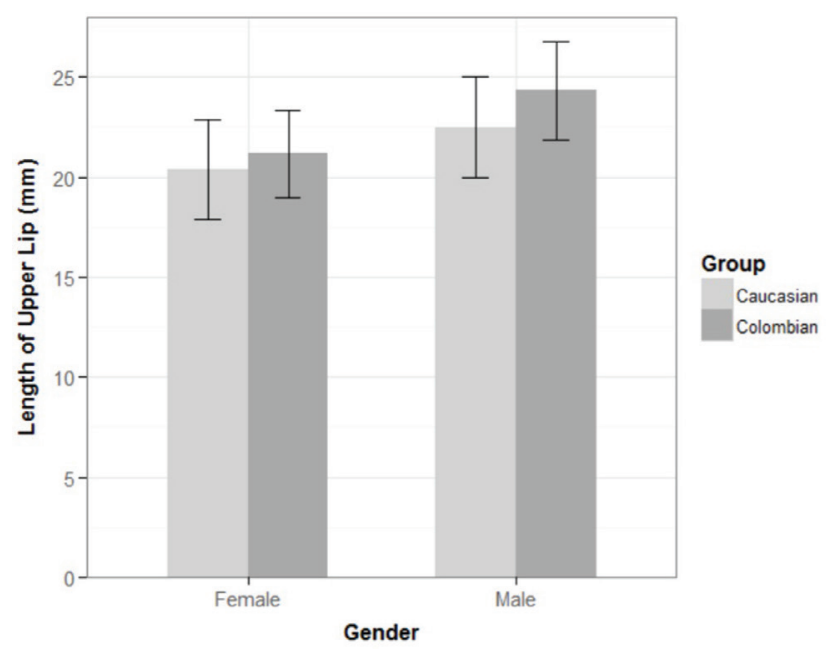

Fig. 4 Comparison of length of upper lip by genre and ethnicity.

longer on males in both ethnicities. The Colombian population showed a bigger upper lip in both genres and the differences were statistically significant ( - Figs. 4 and $\mathbf{5}$ ).

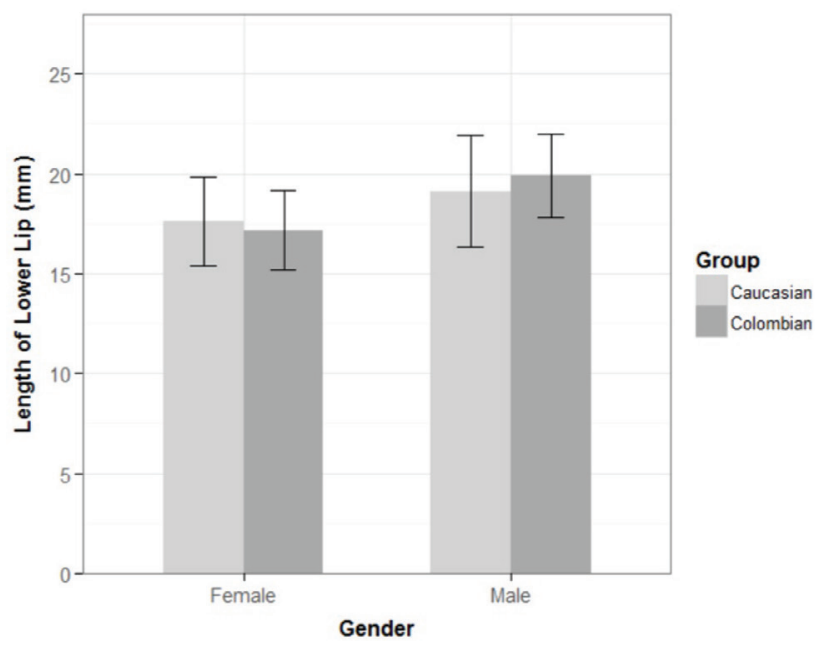

Fig. 5 Comparison of length of upper lip by genre and ethnicity.

\section{Discussion}

Soft tissue measurements are as important as hard tissues and malocclusions during diagnosis and treatment planning 
to evaluate the success of treatment. In the literature, many soft tissue analyses have been published using 3D imaging to describe and evaluate different populations. . $^{10,12,22,23,34}$ In this study, it is evident the facial differences among Caucasians and other ethnicities should be taken into consideration during orthodontic treatment. Many of the described 3D studies above have reported facial morphologies in different ethnicities and compared them with Caucasian races. However, the Hispanic ethnicity has not been studied until now.

The main results of this study showed significant differences between Colombians and Caucasians in the width of the face, mandibular width and protrusion of the lips, which coincide with the results reported by Gonzales and Caruso. ${ }^{35}$ When analyzing the linear measurements, the areas that differed the most were the middle and lower half of the face, which are the areas most influenced by orthodontic treatment.

The present study showed similar observations reported by Velarde and Garcia, who found that Hispanic population had a tendency to maxillary prognatism and protrusive lips. Velarde ${ }^{36}$ concluded that the skeletal pattern had a predisposition toward prognathism of the maxilla and mandible. Another study conducted by Garcia et $\mathrm{al}^{28}$ evaluated MexicanAmerican children using the Downs, Steiner, and Alabama analyses. They determined that the Mexican-American children had more bimaxillary prognathism than Caucasians. Although these studies were done in children using cephalograms, it is evident that the results show a tendency to differ from Caucasian norms from an early age.

With regard to the soft tissue profile, comparison between Colombian males and females, the angle of convexity was more obtuse in males than females, indicating a straighter profile. The greater convexity in males may be due to a more prominent nose and more protruded mandible. These findings coincide with other studies like Fouda, Hafez, and Balut et al. 35,37,38

Gonzalez et al also analyzed cephalograms and found that males and females presented a greater facial convexity and lower face height, which was statistically higher than Caucasians. The nasolabial angle was more obtuse in the Hispanic group $\left(105.4^{\circ}\right)$ when compared with the Caucasian $\left(101^{\circ}\right)$, which was comparable to the results found in the present study.

As far as the vertical heights are concerned, an increase was found in the lower-third facial height in males than females. This could be attributed to the increase in lip length. This significant difference in facial heights between males and females should be considered in treatment planning, because these differences could indicate the increase or decrease of vertical face height. The findings in this study were similar to Anic-Milosevic et a ${ }^{39}$ who compared the height of lips in both genders. They found that the upper and lower lip heights were larger in males, which was also found in the results of this study in both ethnicities, especially larger in males.

Powell and Humphreys ${ }^{40}$ provided a detailed analysis of facial contours and angles on soft tissue profiles. They found that the ideal angles in Caucasians were 115 to $130^{\circ}$ for nasofrontal angle and 120 to $130^{\circ}$ for facial angle of convexity.
Racial variations were evident, with more obtuse nasofrontal and nasomental angles in Chinese as well as the Colombian population.

When the lip protrusion was assessed, the upper and lower lips were found to be more protrusive in the Hispanic population; also, this was more evident in males than in females in both ethnicities. In the study of Powell et al also was found that the upper and lower lips were behind the E-line in Caucasians, but were lying on or anterior to this line in individuals of African or Asian descent. ${ }^{40}$ In this study, the upper and lower lips were behind the E-line but just $2 \mathrm{~mm}$ forward compared with Caucasians in both genres.

With respect to facial proportions, this study showed that males presented the largest middle and lower horizontal thirds compared with females in both ethnicities. These results coincide with the study conducted by Farkas et al, ${ }^{41}$ wherein Caucasians exhibited a middle third smaller than the lower third. However, those results differed from Sim and Smith's study on East Asians, where the middle third of the face was often greater than the upper third and equal to the lower third. ${ }^{42}$

When comparing the jaw position in the anteroposterior plane with the Ricketts analysis, the present study showed marked sexual differences for maxillary prognatism, larger in males $(10.5 \mathrm{~mm})$ compared with females $(8.8 \mathrm{~mm})$, when nasion was the reference point. These results coincide with previous studies in other Hispanic populations where they describe the tendency of Hispanic population to present a more protrusive maxilla when is compared with Caucasians. Several studies have been performed using cephalometric measurements, and it is important to state that 3D values reveal statistically significant correlations with cephalometric values. ${ }^{43}$

\section{Limitations}

One of the deficiencies of the results of this study is the 3D images taken from a Colombian sample that could be slightly different from others Hispanic countries (however, a Colombian sample not necessarily represents all Hispanics). Another disadvantage of this study could be the reliability of the landmarks and the number of operators that collaborated in other studies; however, it is important to notice that the measurements are similar in several landmarks, indicating a good reliability in the overall facial analysis. In this study, this aspect was controlled by calibration of the main examiner which demonstrated a good reproducibility of the landmarks. Forming the database for adult Colombians gave an opportunity for future research to visualize the 3D face with hard tissues. This would also allow researchers to compare differences in facial morphology for better treatment decisions.

\section{Conclusions}

From this study, the following conclusions may be drawn:

1. The mean values of Colombian males showed greater measurements than females in the majority of measurements. 
2. Colombian females had bigger eyes, more protrusive lips, and wider facial and gonial width compared with females Caucasians.

3. Colombian males had longer upper lips, bigger eyes, slightly more prominent noses, more protrusive lips, as well as broader gonial and facial widths compared with males Caucasians.

4. Caucasian females had a more acute full profile, larger middle and lower third, and less protrusive lips.

5. The Colombians had more protruded upper and lower lips, wider eyes, zygomatic, and mandibular widths.

6. This study showed significant ethnic differences in the linear and angular measurements, showing us the importance to consider these findings in the diagnosis and treatment planning when a Hispanic population is involved. Soft tissue values should reflect the norms according to each ethnic population to achieve treatment goals.

\section{Conflict of Interest}

None declared.

\section{References}

1 Mah J, Sachdeva R. Computer-assisted orthodontic treatment: the SureSmile process. Am J Orthod Dentofacial Orthop 2001;120(1):85-87

2 Kau CH, Hunter LM, Hingston EJ. A different look: 3dimensional facial imaging of a child with Binder syndrome. Am J Orthod Dentofacial Orthop 2007;132(5):704-709

3 Palomo JM, Kau CH, Palomo LB, Hans MG. Three-dimensional cone beam computerized tomography in dentistry. Dent Today 2006;25(11):130-132-135

$4 \mathrm{Kau} \mathrm{CH}$. Creation of the virtual patient for the study of facial morphology. Facial Plast Surg Clin North Am 2011; 19(4):615-622

5 Creed B, Kau CH, English JD, Xia JJ, Lee RP. A comparison of the accuracy of linear measurements obtained from cone beam computerized tomography images and digital models. Semin Orthod 2011;17(1):49-56

6 Torassian G, Kau CH, English JD, et al. Digital models vs plaster models using alginate and alginate substitute materials. Angle Orthod 2010;80(4):474-481

7 Ireland AJ, McNamara C, Clover MJ, et al. 3D surface imaging in dentistry - what we are looking at. Br Dent J 2008; 205(7):387-392

8 Lightheart KG, English JD, Kau $\mathrm{CH}$, et al. Surface analysis of study models generated from OrthoCAD and cone-beam computed tomography imaging. Am J Orthod Dentofacial Orthop 2012;141(6):686-693

9 Kau CH, Cronin AJ, Richmond S. A three-dimensional evaluation of postoperative swelling following orthognathic surgery at 6 months. Plast Reconstr Surg 2007;119(7):2192-2199

10 Bo Ic M, Kau CH, Richmond S, et al. Facial morphology of Slovenian and Welsh white populations using 3-dimensional imaging. Angle Orthod 2009;79(4):640-645

11 Hajeer MY, Ayoub AF, Millett DT. Three-dimensional assessment of facial soft-tissue asymmetry before and after orthognathic surgery. Br J Oral Maxillofac Surg 2004;42(5):396-404

12 Gor T, Kau CH, English JD, Lee RP, Borbely P. Three-dimensional comparison of facial morphology in white populations in Budapest, Hungary, and Houston, Texas. Am J Orthod Dentofacial Orthop 2010;137(3):424-432
13 Marmulla R, Hassfeld S, Lüth T, Mende U, Mühling J. Soft tissue scanning for patient registration in image-guided surgery. Comput Aided Surg 2003;8(2):70-81

$14 \mathrm{Kau} \mathrm{CH}$, Kamel SG, Wilson J, Wong ME. New method for analysis of facial growth in a pediatric reconstructed mandible. Am J Orthod Dentofacial Orthop 2011;139(4):e285-e290

15 Wirthlin J, Kau CH, English JD, Pan F, Zhou H. Comparison of facial morphologies between adult Chinese and Houstonian Caucasian populations using three-dimensional imaging. Int J Oral Maxillofac Surg 2013;42(9):1100-1107

16 Ackerman JL, Proffit WR, Sarver DM. The emerging soft tissue paradigm in orthodontic diagnosis and treatment planning. Clin Orthod Res 1999;2(2):49-52

17 Weinberg SM. 3D stereophotogrammetry versus traditional craniofacial anthropometry: Comparing measurements from the 3D facial norms database to Farkas's North American norms. Am J Orthod Dentofacial Orthop 2019;155(5): 693-701

18 Tolleson SR, Kau CH, Lee RP, et al. 3-D analysis of facial asymmetry in children with hip dysplasia. Angle Orthod 2010;80(4):519-524

19 Kim JY, Kau CH, Christou T, Ovsenik M, Guk Park Y. Threedimensional analysis of normal facial morphologies of Asians and Whites: a novel method of quantitative analysis. Plast Reconstr Surg Glob Open 2016;4(9):e865

20 Kau CH, Wang J, Davis M. A cross-sectional study to understand $3 \mathrm{~d}$ facial differences in a population of African Americans and Caucasians. Eur J Dent 2019;13(4):485-496

21 Talbert L, Kau CH, Christou T, Vlachos C, Souccar N. A 3D analysis of Caucasian and African American facial morphologies in a US population. J Orthod 2014;41(1):19-29

22 Kau CH, Richmond S, Zhurov A, et al. Use of 3-dimensional surface acquisition to study facial morphology in 5 populations. Am J Orthod Dentofacial Orthop 2010;137(4(Suppl):56.e1-56. e9, discussion S56-S57

23 Liu Y, Kau CH, Pan F, Zhou H, Zhang Q, Zacharopoulos GV. A 3-dimensional anthropometric evaluation of facial morphology among Chinese and Greek population. J Craniofac Surg 2013;24(4):e353-e358

$24 \mathrm{Kau} \mathrm{CH}$, Richmond S. Three-dimensional analysis of facial morphology surface changes in untreated children from 12 to 14 years of age. Am J Orthod Dentofacial Orthop 2008;134(6):751-760

25 Kau CH, Richmond S, Incrapera A, English J, Xia JJ. Threedimensional surface acquisition systems for the study of facial morphology and their application to maxillofacial surgery. Int J Med Robot 2007;3(2):97-110

26 CanavatiP. Cephalometric Standards for Four and Five Year Old Latin American Children [unpublished master's thesis]. University of Texas; 1967

27 KennedyP. Cephalometric Standards of Four, Five Six, and Seven Year Old Latin American Children [unpublished master's thesis]. University of Texas, Austin, Texas; 1969

28 Garcia CJ. Cephalometric evaluation of Mexican Americans using the Downs and Steiner analyses. Am J Orthod 1975;68(1): 67-74

29 Swlerenga D, Oesterle LJ, Messersmith ML. Cephalometric values for adult Mexican-Americans. Am J Orthod Dentofacial Orthop 1994;106(2):146-155

30 Vela E, Taylor RW, Campbell PM, Buschang PH. Differences in craniofacial and dental characteristics of adolescent Mexican Americans and European Americans. Am J Orthod Dentofacial Orthop 2011;140(6):839-847

31 Weber DW, Fallis DW, Packer MD. Three-dimensional reproducibility of natural head position. Am J Orthod Dentofacial Orthop 2013;143(5):738-744 
32 Lübbers HT, Medinger L, Kruse A, Grätz KW, Matthews F. Precision and accuracy of the 3dMD photogrammetric system in craniomaxillofacial application. J Craniofac Surg 2010;21(3):763-767

33 ZhurovAI KC, RichmondS. Computer methods for measuring 3D facial morphology. In: Proceedings of CMBBE2004. Middleton J, Shrive MG, Jones ML, eds., First Numerics Ltd.: 2014

34 Liu Y, Kau CH, Talbert L, Pan F. Three-dimensional analysis of facial morphology. J Craniofac Surg 2014;25(5):1890-1894

35 Gonzalez MB, Caruso JM, Sugiyama RM, Schlenker WL. Establishing cephalometric norms for a Mexican population using Ricketts, Steiner, Tweed and Arnett analyses. APOS Trends Orthod 2013;3:171-177

36 VelardeE. Norms for the Mexican Population using the Tweed, Steiner and Ricketts Analysis. [unpublished master's thesis]. Loma Linda University, California, USA; 1974

37 Fouda M. Sexual demorphism of cephalometric norms. Al Azhar Dent J 1987;2:563e76
38 Hafez S. Soft tissue facial profile changes from 11 to 22 years of age for Egyptian males. Egypt Dent J 2003;49:807-826

39 Anic-Milosevic S, Mestrovic S, Prlić A, Slaj M. Proportions in the upper lip-lower lip-chin area of the lower face as determined by photogrammetric method. J Craniomaxillofac Surg 2010;38(2):90-95

40 N. Powell N BH, Proportions of the aesthetic face. New York: Thieme-Stratton; 1984

41 Farkas LG, Hreczko TA, Kolar JC, Munro IR; LG. Vertical and horizontal proportions of the face in young adult North American Caucasians: revision of neoclassical canons. Plast Reconstr Surg 1985;75(3):328-338

42 Sim RST, Smith JD, Chan AS. Comparison of the aesthetic facial proportions of southern Chinese and white women. Arch Facial Plast Surg 2000;2(2):113-120

43 Kochel J, et al. Sagittal parameters of 3D soft tissue analysis. J Orofac Orthop 2010;(1):40-50 